\title{
A short guide to being mentored Tips for strong relationships
}

I $n$ the past several decades, scores of books about mentoring and librarianship have been published. There are academic articles, webinars, and workshops that librarians can use to learn more about why mentoring is important and how to be a good mentor. However, in my own experience, most of these resources explore mentoring from the perspective of the mentor, not the mentee.

When I graduated from library school, my colleague Andrew Walsh and I began researching mentoring in academic libraries for an article that was eventually published in College $\&$ Research Libraries. ${ }^{1}$ As part of the research process, I decided to join as many mentoring programs as I could find to see what I could learn from the experience. In the intervening six years, I have continued to participate in mentoring programs at the national, state, and local level, and have even started one at my own library. In total, I have participated in seven formal mentoring programs.

Besides benefiting considerably from many of the mentoring relationships, I also learned a great deal about what makes a mentoring relationship successful from the mentee's point of view. I found out the hard way that there are plenty of actions and skills that the mentee can bring to the table to improve the relationship_but I, much like many other mentees, had never gotten any training or guidance in what I was supposed to do as the mentee. I just thought that I was supposed to show up and "get mentored." What I learned was how much richer and more valuable a mentoring relationship can be from the mentee perspective with a little bit of effort and training. Below are my tips for how to establish a strong mentoring relationship from the perspective of a mentee. ${ }^{2}$

1. Commit. Being in a mentoring relationship means committing time and energy to the relationship and its goals. Usually this is more of a concern for mentors, who are taking time to focus on the development of another professional and may not be as motivated. However, even though the mentee is the one benefiting, the mentee should consider how to make the time to attend meetings, respond to mentor emails, and work on the issues that come up during conversations with the mentor. Your mentor shouldn't be nagging you to meet or feel that you aren't valuing your time together in meetings.

Mandi Goodsett is performing arts and humanities librarian at Cleveland State University, email:.goodsett@ csuohio.edu

() 2019 Mandi Goodsett 
2. Plan. While many formal mentoring programs now incorporate goal-setting as a component of program participation, even if it isn't required, you may want to take some time to set several specific goals for your mentoring relationship. What skills would you like to develop? What products do you want to make? Having these goals from the beginning will help direct the discussions you have with your mentor.

3. Prepare. I learned the hard way that a quick way for a mentoring relationship to fizzle out is to attend mentoring meetings without any plan for what to discuss. As the mentee, you should be prepared with questions, scenarios, and updates when you meet with your mentor, or your meeting will appear pretty pointless. In between meetings, consider writing down questions or problems that you encounter in the workplace as they occur. Preparing with some topics and questions can go a long way toward making your mentoring meetings more valuable for both you and your mentor.

4. Listen. Some of the most effective mentors I've had gave me advice that I didn't want to hear. Sometimes they warned against my intended course of action or advised me to take an approach that I didn't initially want to take. While not all of this advice was good, much of it was very important, and I appreciated the results I got when I took it, even if it took me a while to have that feeling of appreciation. Weigh your own interests and experiences against your mentor's advice, of course, but try to have an open mind to their advice, especially when it conflicts with what you really want to do. This can be the greatest value of your mentoring relationship.

5. Collaborate. While it isn't necessary to have a strong mentoring relationship, I have found that mentoring experiences that resulted in or revolved around a shared project tend to be the most meaningful. Compare your research interests with your mentor's. Are there any problems you are both encountering at your libraries or any research interests that overlap? These might be a great starting place for a coauthored article, a conference presentation, or another research project. A project like this can ground your discussions with your mentor, teach you more about the research process, and result in a product that you both can list on your CVs. Overall, when this is possible, it's a win for both you and your mentor.

6. Read up. If you are interested in mentoring and want to learn more, there are many resources available to you. Feel free to check out and share the bibliography I created-your mentor might want to take a look at it too! ${ }^{3}$

Participating in a mentoring relationship can be incredibly valuable and rewarding, both for you and for your mentor. However, librarians don't just wake up one day knowing how to be good mentees, and most of us aren't trained in that area either. Hopefully these few small changes to your approach to the mentoring experience can result in a relationship that is more productive, fulfilling, and memorable.

\section{Notes}

1. Mandi Goodsett and Andrew Walsh, "Building a Strong Foundation: Mentoring Programs for Novice Tenure-Track Librarians in Academic Libraries," College $\varepsilon$ Research Libraries 76 (2015): 914-33, https://doi.org/10.5860 /crl.76.7.914.

2. This advice assumes a formal, traditional dyad mentoring relationship (one more experienced mentor and one less experienced mentee). However, many non-traditional mentoring configurations are becoming more popular and can be great alternative options. Some of this advice may still apply in these relationships, or to less formal dyad relationships too.

3. See https://tinyurl.com /librarianmentoring. 